\title{
Avaliação da Sensibilidade Dentária duRANTE a RemoçÃo Seletiva de Lesões de CÁRIE EM DeNTES decíduos UTILIZANDO LASER DE ER:YAG
}

Dissertação apresentada à Faculdade de Odontologia de Ribeirão Preto da Universidade de São Paulo, para obtenção do título de Mestre em Ciências. Programa: Odontopediatria Área de concentração: Odontopediatria

Orientadora: Profa. Dra. Silmara Aparecida Milori Corona

Ribeirão Preto 
Autorizo a reprodução e divulgação total ou parcial deste trabalho, por qualquer meio convencional ou eletrônico, para fins de estudo e pesquisa, desde que citada a fonte.

FICHA CATALOGRÁFICA

Polizeli, Silvana Aparecida Fernandes

Avaliação da sensibilidade dentária durante a remoção seletiva de lesões de cárie em dentes decíduos utilizando laser de Er:YAG. Ribeirão Preto, 2013.

60 p.: il, $30 \mathrm{~cm}$.

Dissertação de Mestrado apresentada à Faculdade de Odontologia de Ribeirão Preto da Universidade de São Paulo. Área de concentração: Odontopediatria.

Orientadora: Corona, Silmara Aparecida Milori

1. Laser de Er:YAG; 2. Sensibilidade dentária; 3. Dentes decíduos; 4. Remoção seletiva de lesões de cárie 
POLIZELI, SAF. Avaliação da sensibilidade dentária durante a remoção seletiva de lesões de cárie em dentes decíduos utilizando laser de Er:YAG.

Dissertação apresentada à Faculdade de Odontologia de Ribeirão Preto da Universidade de São Paulo para obtenção do Título de Mestre em Ciências. Programa: Odontopediatria. Área de concentração: Odontopediatria.

Aprovado em:

\section{Banca Examinadora}

Prof. Dr.

Instituição:

Julgamento: Assinatura:

Prof. Dr.

Instituição:

Julgamento: Assinatura:

Prof. Dr. Instituição: Julgamento: Assinatura: 


\title{
DADOS CURRICULARES
}

\section{Silvana Aparecida Fernandes Polizeli}

\author{
Nascimento 05 de setembro de 1971 \\ Natural de Mogi das Cruzes/SP \\ Filiação Francisco Fernandes \\ Aparecida Maria Fernandes
}

1992-1997 Graduação em Odontologia - Universidade de Mogi das Cruzes

1998-2000 Curso de aperfeiçoamento em Ortodontia Preventiva e Interceptativa SOESP (Sindicato dos Odontologistas do Estado de São Paulo)

1999-1999 Curso de aperfeiçoamento em cirurgia oral -APCD -Vila Mariana

2011-2011 Curso de aperfeiçoamento em Acupuntura para Pacientes Especiais

2012-2012 Curso de aperfeiçoamento em Atendimento Odontológico a

Pacientes Especiais. FORP - USP.

2011-2013 Especialização em Odontopediatria - AORP

2011-2013 Curso de pós-graduação (Mestrado) em odontologia.

Área de concentração: Odontopediatria - FORP / USP 
Dedicatória 
Dedico este trabalho,

A DEUS primeiramente, pelo Dom da vida, Ele é que torna tudo possível, inclusive a possibilidade de enfrentar obstáculos jamais imaginados.

Ao meu Mestre, amigo de todas as horas, que por meio do seu exemplo me mostra sempre o caminho de um "Mundo Bem Melhor".

Aos meus pais Francisco e Maria, exemplos de honestidade, amor, família. Meu porto seguro, sem vocês "por perto", mesmo que distantes, não seria possível tudo isso. Como eu digo sempre, vocês são os pais que eu escolheria por todas as minhas vidas....amo vocês!

Ao meu grande amor Sandro, meu cúmplice, companheiro de toda uma vida, por me entender nas ausências, e por estar sempre ao meu lado.

Ao meu filho Lucca, luz da minha vida, obrigada por tentar entender a vida corrida dos adultos sempre com boas e sábias palavras, você é a coisa mais importante da minha vida. Amo muito você.

Ao meu filho Matheus, sobrinho que se permitiu ser filho, meu exemplo é sempre pra você! Te amo.

Ao meu irmão Leonardo, meu querido, sempre com palavras de conforto nos momentos difíceis.

A minha orientadora Profa. Dra. Silmara Aparecida Milori Corona, a melhor orientadora que eu podia ter, conviver com você é sempre muito bom e divertido.

Sil, você é muito especial. 
Ao meu amigo, Rodrigo Alexandre Valério, por entender minha correria, pelas risadas, pelo exemplo de grande pessoa que você é, companheiro, sempre disposto a ajudar, sem você eu não teria chegado até aqui. Ro, você vai estar sempre no meu coração! 
Agradecimentos Especiais 
À minha família pelo amor e união, onde todas as dificuldades são vencidas e as alegrias compartilhadas.

Às amigas, Ana Caroline, Denise, Katharina, Priscilla, Mariana, Larissa, Driely, Barbara, Karina, Danielly, Leticia e Talita pela amizade durante o mestrado, cada uma de vocês ía deixou lembranças muito boas na minha vida, obrigada por tudo. Lari, Dri e Ba...saudades dos bons momentos que passamos juntas. Mari, é muito bom ter você por perto.

A Profa. Dra. Maria Cristina Borsatto, pela alegria e companheirismo de sempre.

A Profa. Dra. Mônica Campos Serra, por estar sempre por perto, disponível, me ajudando com o seu conhecimento e amizade a repensar muitos aspectos da odontologia.

Ao Prof. Dr. Antonio Luiz Rodrigues Júnior, do Departamento de Medicina Social da Faculdade de Medicina de Ribeirão Preto - USP, pelo auxîlio com a análise estatística deste trabalho.

Aos docentes do departamento de Clínica Infantil e Social da Faculdade de Odontologia de Ribeirão Preto, São Paulo, Profas. Dras. Aldevina Campos de Freitas, Alexandra Mussolino de Queiroz, Andiara De Rossi, Kranya Victoria Díaz Serrano, Léa Assed Bezerra da Silva, Raquel Assed Bezerra da Silva, Sada Assed, Maria Bernadete Sasso Stuani, Mírian Aiko Nakane Matsumoto, Maria da Conceição Pereira Saraiva e aos Profs. Drs. Paulo Nelson Filho, Adîlson Tomasin, Fábio Lourenço Romano, José Tarcísio Lima Ferreira, pelos ensinamentos, amizade e atenção.

As crianças que participaram deste trabalho, sem as quais a realização deste estudo não seria possível. 
Algradecimentos 
À Faculdade de Odontologia de Ribeirão Preto, da Universidade de São Paulo, na pessoa do diretor Prof. Dr. Valdemar Mallet da Rocha Barros e a Vice-Diretora Profa. Dra. Léa Assed Bezerra da Silva.

A Coordenação do Curso de Pós-Graduação da Faculdade de Odontologia de Ribeirão Preto da Universidade de São Paulo, na pessoa do Prof. Dr. Arthur Belém Novaes Júnior.

A Coordenação do Curso de Pós-Graduação da Faculdade de Odontologia de Ribeirão Preto da Universidade de São Paulo, área de concentração em Odontopediatria na pessoa da Profa. Dra. Léa Assed Bezerra da Silva e do Vice-Coordenador Prof. Dr. Paulo Nelson Filho.

Aos funcionários do Departamento de Clínica Infantil, Odontologia Preventiva e Social e da Clínica de Pacientes Especiais da Faculdade de Odontologia de Ribeirão Preto, Universidade de São Paulo: Filomena, Micheli, Matheus, Francisco, Carolina, Marco, Marîlia, Carmo, Nilza, Fátima Rizoli, Fátima Daniel, Renata, "Seu" Zé, Verinha e Ditinha, pela amizade, disponibilidade, paciência e ajuda, vocês também foram meus mestres durante esta etapa.

As funcionárias da seção de Pós-Graduação da Faculdade de Odontologia de Ribeirão Preto da Universidade de São Paulo, Isabel e Regiane, obrigada pela amizade, atenção e paciência em todos os momentos.

Aos funcionários do Departamento de Odontologia Restauradora da Faculdade de Odontologia de Ribeirão Preto - Universidade de São Paulo: Carlos, Amălia, Bel, Rosângela, Reginaldo, Luiza e Patrícia, pela atenção e colaboração durante o mestrado.

Aos Funcionários da Biblioteca (BCRP) Maria Cristina e Robson, pela paciência e disponibilidade na conferência das referências bibliográficas deste trabalho. 
Aos alunos do Curso de Pós-graduação Giselle, Danielle, Késsia, Fernanda, Marina, Marta, Cíntia, Camila, Daniel, Renata, Taísa, Juliana, Gabriela, Daniela, Marilia e Lidia pela amizade e pelos bons momentos.

Ao Prof. Dr. Rodrigo Galo, pela alegre convivência e ajuda.

A Renata e Taisa pelos "palpites" e por estarem sempre disponíveis.

A FAPESP (Proc. 2011/00272-5), pela concessão de Auxîlio Pesquisa, o que permitiu a execução deste trabalho.

A CAPES pela bolsa concedida. 
Epigrafe 
"A mente que se abre a uma nova ideia jamais voltará ao seu tamanho original" Albert Einstein 
Sumário 
RESUMO

ABSTRACT

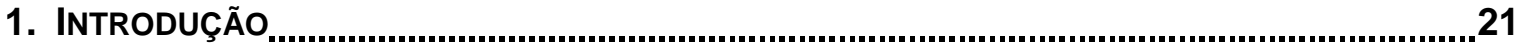

2. PROPOSIÇÃO

3. MATERIAL E MÉTODO

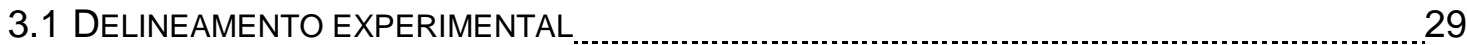

3.2 SELEÇÃO DAS CRIANÇAS

3.3 SELEÇÃO DOS DENTES

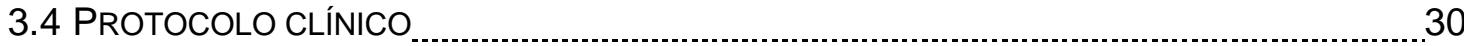

3.5 AVALIAÇÃO DA SENSIBILIDADE

3.6 TRATAMENTO RESTAURADOR

3.7 AVALIAÇÃO DA PREFERÊNCIA

3.8 ANÁLISE ESTATÍSTICA

4. RESULTADOS

5. DISCUSSÃO

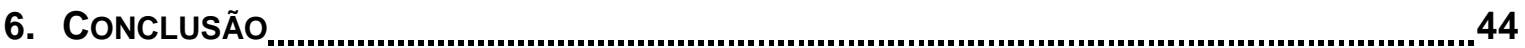

REFERÊNCIAS

ANEXOS 
Resumo 
Polizeli, S A F. Avaliação da sensibilidade dentária durante a remoção seletiva de lesões de cárie em dentes decíduos utilizando laser de Er:YAG. [dissertação].Ribeirão Preto: Faculdade de Odontologia de Ribeirão Preto da Universidade de São Paulo; 2013. 60p.

A realização de preparos cavitários que removam menor quantidade de substrato dentário sadio, oferecendo maior conforto e menor sensibilidade durante 0 tratamento odontológico em crianças, associado ao emprego de materiais restauradores estéticos adesivos são procedimentos comumente empregados na odontologia minimamente invasiva. O presente estudo tem por objetivo avaliar a sensibilidade dentária durante a remoção seletiva das lesões de cárie e preparo cavitário em dentes decíduos e o método de remoção de tecido cariado preferido pelas crianças. Foram selecionadas 20 crianças entre 7 e 10 anos, apresentando pelo menos duas lesões de cárie ativas, com cavitação atingindo dentina localizadas na superfície oclusal de molares decíduos homólogos. Os dentes de cada criança foram distribuídos aleatoriamente em dois grupos: (I) Laser de Er:YAG (250mJ / 4 $\mathrm{Hz}$ ), para remoção do esmalte cavo superficial e remoção seletiva da lesão de cárie associado a curetas e (II) Método Convencional (turbina de alta rotação para remoção do esmalte cavo-superficial e turbina de baixa rotação para a remoção seletiva do tecido cariado associado a curetas). A sensibilidade dentária foi analisada durante a remoção seletiva de lesões de cárie e preparo cavitário, empregando a escala facial analógica. A preferência pelo método de remoção de tecido cariado pelas crianças foi avaliado após 7 dias da realização das restaurações. Nas cavidades médias foi realizada proteção pulpar indireta com cimento de ionômero de vidro (Ketac Molar - 3M), nas cavidades profundas foi realizada proteção pulpar indireta utilizando cimento de hidróxido de cálcio (Dycal Dentisply) e cimento de ionômero de vidro (Ketac Molar - 3M). Todas as cavidades preparadas foram restauradas empregando o sistema restaurador Adper Single Bond 2 / Filtek Supreme (3M). Os dados obtidos relativos à sensibilidade dentária foram submetidos ao teste de Fischer e os resultados não indicaram associação entre os tratamentos realizados e a face indicada pela criança $(p=0,065)$, na escala facial analógica. Em relação à preferência pelo método de remoção seletiva de lesões de cárie, 90\% das crianças optaram pela utilização do laser de Er:YAG. Considerando a metodologia utilizada e os resultados obtidos pode-se concluir que independente do método utilizado, convencional ou laser de Er:YAG, a sensibilidade dentária não foi alterada durante a remoção seletiva de lesões de cárie, no entanto o laser foi o método preferido pela grande maioria das crianças.

Palavras-Chave: Laser de Er:YAG, sensibilidade dentária, dentes decíduos, remoção seletiva de lesões de cárie 
Polizeli, S A F. Evaluation of tooth sensitivity during the selective carious lesions removal in primary teeth using Er:YAG laser. [dissertação].Ribeirão Preto: Faculdade de Odontologia de Ribeirão Preto da Universidade de São Paulo; 2013. 60p.

Cavity preparations removing fewer sound dental substrates, providing greater comfort and less sensitivity during the dental treatment in children, associated to the use of adhesive esthetic restorative materials are procedures usually employed in minimally invasive dentistry. The present study aimed to evaluate the tooth sensitivity during the selective carious lesions removal and cavity preparation in primary teeth and the preference by the method employed to remove the carious tissue. Twenty children aged between 7-10 year, who presented at least two active carious lesions with cavitation reaching dentine, located on the occlusal surface of homologous primary molars, were selected. The teeth of each child was randomly assigned to one of these groups: (I) Er:YAG laser $(250 \mathrm{~mJ} / 4 \mathrm{~Hz})$ to remove the cavosurface enamel and selective carious lesion removal associated with curettes, and (II) Conventional Method (high speed turbine to remove the cavosurface enamel and low speed turbine to selective carious tissue removal associated with curettes). The tooth sensitivity was assessed during the selective carious tissue removal and cavity preparation, using an analog facial scale, and the preference by the method of selective removal of carious tissue was evaluated 7 days after the tooth restoration. At cavities with medium depth, an indirect pulp capping was performed with glassionomer cement (Ketac Molar - 3M) and at deep cavities, the indirect pulp capping was performed with calcium hydroxide cement (Dycal - Dentsply) plus glass-ionomer cement (Ketac Molar - 3M). All of them were restored using the restorative system Adper Single Bond 2 / Filtek Supreme (3M). The data related to the tooth sensitivity were subjected to Fischer's test and the results indicated no association between the experimental treatments and the face indicated by the child $(p=0,065)$ at the analog facial scale. Regarding the preference by the method of selective carious tissue removal, $90 \%$ of the children chose the employ of Er:YAG laser. It can be concluded that the Er:YAG laser had no influence at tooth sensitivity during the selective carious lesions removal at primary teeth, however, it was the preferred method by children.

Keywords: Er:YAG laser, tooth sensitivity, primary teeth, selective removal of carious lesion 
1. Introdução 


\section{INTRODUÇÃO}

O desequilíbrio dos fenômenos de desmineralização-remineralização promove o desenvolvimento da doença cárie, onde grande quantidade de minerais são perdidos pelos tecidos dentários (Thylstrup, 1988). Quando o esmalte dentário é exposto aos ácidos formados durante o metabolismo bacteriano, seus minerais são removidos dos cristais de hidroxiapatita, que reduz seu tamanho e amplia os espaços intercristalinos, aumentando a porosidade da superfície dentária, promovendo uma progressão mais rápida das lesões de cárie em dentes decíduos, uma vez que, a espessura do esmalte e dentina do dente decíduo é menor que o esmalte e a dentina do dente permanente (Mortimer, 1970), além de apresentar diferente translucidez, maior porosidade e menor conteúdo mineral que os dentes permanentes (Mortimer,1970; Low et al., 2008; De Menezes Oliveira et al., 2010).

A odontologia minimamente invasiva compreende a máxima preservação do substrato dentário sadio em todos os procedimentos odontológicos (Tyas et al., 2000). Quando os métodos preventivos não são aplicados adequadamente, ocorre a instalação das lesões de cárie e o preparo da cavidade torna-se necessário, sendo assim, a remoção de tecido dentário deve ser a mais limitada possível, pois nenhum material restaurador existente tem condições de suprir completamente as características funcionais do esmalte, da dentina e do cemento quando esses substratos se apresentam sadios na cavidade bucal. Essa visão de mínima intervenção e máxima preservação dos tecidos dentários torna importante e indispensável à distinção clínica entre a dentina infectada (necrosada) e a dentina afetada (remineralizável), uma vez que essas características são de fundamental importância e tem caráter decisivo entre o que deve ser removido e o que pode ou convém ser preservado durante a remoção de tecido cariado (Massara et al., 2002).

A dentina infectada corresponde à camada mais externa do tecido cariado, apresentando-se como um tecido infectado, necrótico e irreversivelmente desorganizado, enquanto que, a dentina afetada está localizada mais internamente, sendo menos desorganizada e potencialmente remineralizável (Fusayama, 1979). O sucesso desta terapia se baseia na seletividade da remoção do tecido cariado (Banerjee et al., 2000; Kidd, 2004), a qual reduz a quantidade de bactérias no 
interior da cavidade sem remover o tecido cariado passível de remineralização (Kidd, 2004; Maltz et al., 2007; Thompson et al., 2008; Maltz et al., 2012).

O isolamento das lesões de cárie por meio do selamento das cavidades, promovem mudanças no microambiente, com redução significativa da contaminação devido a redução da quantidade de nutrientes dos micro-organismos (Bjorndal et al., 1997; Bjorndal e Larsen, 2000; Massara et al., 2002; Paddick et al., 2005; Pinto et al., 2006; Wambier et al., 2007; Duque et al., 2009; Lula et al., 2009), resultando numa microbiota sobrevivente menos complexa (Paddick et al., 2005). A técnica de remoção seletiva de tecido cariado torna-se interessante e preferível, quando comparada à remoção total do tecido cariado, uma vez que, os substratos dentários sadios são preservados, promovendo menor risco de exposição pulpar (Ricketts et al., 2006; Thompson et al., 2008), e consequentemente o selamento da cavidade promove a paralisação da lesão, estimulando o processo de esclerose tubular e deposição de dentina terciária, reduzindo assim a permeabilidade da dentina remanescente (Kidd, 2004).

A busca constante por procedimentos que proporcionem ao paciente um tratamento menos traumático e mais conservador durante os procedimentos odontológicos, tem originado o desenvolvimento de tecnologias para a realização de preparos cavitários, alternativas aos instrumentos rotatórios convencionais em alta e baixa rotação, como a abrasão a ar, tecnologia esta que permite rápida remoção de esmalte, dentina, tecido cariado e restaurações insatisfatórias por meio do bombardeamento da superfície dentária por partículas de óxido de alumínio em alta velocidade (Sazak et al., 2001); o Carisolv®, método químico-mecânico que desnatura o colágeno da dentina cariada, permitindo sua remoção com a utilização de curetas especiais (Cederlund et al., 1999); as pontas diamantadas com tecnologia CVD (Chemical Vapor Deposition) (CVDentus ${ }^{\circledR}$ ), acopladas ao ultrasom, que produzem desgastes devido ao movimento oscilatório (Hugo; Stassinakis, 1998); e o laser de Er:YAG, cujo comprimento de onda de 2,94 $\mu \mathrm{m}$, coincide com 0 pico máximo de absorção da água e dos radicais hidroxila presentes na hidroxiapatita (Paghdiwala, 1991; Keller; Hibst, 1997), que promove a ablação eficaz e eficiente do tecido cariado (Aoki et al.,1998), removendo-o por meio de micro explosões originadas da evaporação da água contida no tecido mineralizado (Hibst; Keller,1989), tornando a superfície dentinária livre de smear layer e com túbulos dentinários abertos (Aoki et al., 1998), sendo utilizado para remoção de lesões de 
cárie em dentes permanentes (Aoki et al., 1998; Dommisch et al., 2008) e decíduos (Keller; Hibst, 1997; Evans et al., 2000; Kato et al., 2003; Liu et al., 2006; Jacobson; Asgari, 2008; Kornblit et al., 2008; Krause et al., 2008) .

Os efeitos do laser de érbio nos tecidos duros dentais dependem dos parâmetros utilizados e do tipo de substrato irradiado (Keller; Hibst, 1997). Como a eficiência do laser depende da sua interação com o tecido (Armengol et al., 2000), para uma mesma energia radiante, a ablação é mais eficiente na dentina que no esmalte, devido ao seu alto conteúdo de água (Armengol et al., 2000; Freitas et al., 2007). As diferenças morfológicas entre a dentina de dentes decíduos e permanentes também interferem no mecanismo de ablação do laser, devido à presença da dentina peritubular, que nos dentes decíduos é de 2 a 5 vezes mais espessa do que em dentes permanentes (Hirayama et al., 1986; Sumikawa et al., 1999). A densidade numérica e o calibre dos túbulos dentinários em dentes decíduos também são maiores e, portanto, a área de dentina intertubular disponível é menor, podendo causar uma diferença significante na capacidade de ablação do laser, ou seja, a remoção de tecidos provenientes de dentes decíduos é maior que dos dentes permanentes (Lizarelli et al., 2003; Kornblit et al., 2008), devido a penetração do feixe de laser ser mais pronunciada na dentina dos dentes decíduos (Lizarelli et al., 2003).

A odontologia está em constante busca por procedimentos que removam o tecido dental cariado com segurança biológica, oferecendo maior conforto ao paciente e ao profissional, eliminando a vibração, pressão e os ruídos emitidos pelo uso de aparelhos rotatórios convencionais durante o preparo cavitário (Keller; Hibst, 1997; Cozean et al., 1997; Evans et al., 1998) principalmente no atendimento odontológico de crianças, as quais relacionam esse medo com experiências subjetivas de dor e trauma e não com a patologia dental propriamente dita (Townend et al., 2000). A aquisição e perpetuação de atitudes negativas diante do tratamento odontológico é um processo que na maioria das vezes tem início na infância (Abreu et al., 2011), e pode persistir na adolescência, o que muitas vezes leva o indivíduo a apresentar um comportamento considerado inadequado até a idade adulta, evitando o tratamento odontológico (Chapman; Kirby-Tumer, 1999).

A ansiedade e o pânico durante o tratamento odontológico restaurador, especialmente em pacientes infantis, podem ser reduzidos consideravelmente frente à utilização do laser de Er:YAG na remoção de lesões de cárie, permitindo que 
esses procedimentos se tornem mais confortáveis para o paciente (Keller et al., 1998). A utilização da tecnologia laser elimina o desconforto produzido pelo ruído e vibração dos instrumentos rotatórios convencionais e torna menor a necessidade do uso de anestesia local infiltrativa (Keller; Hibst, 1997; Pelagalli et al., 1997; Kato et al., 2003; Takamori et al., 2003; Krause et al., 2008). A utilização do laser de Er:YAG na remoção de tecido cariado tem sido bem aceita pelos pacientes (Cozean et al., 1997; Keller; Hibst, 1997), apesar de exigir maior tempo de trabalho (Aoki et al., 1998; Hossain et al., 2003).

O emprego dessa tecnologia para remoção de tecido dentário cariado (Cozean et al., 1997), tem proporcionado um aumento no número de pesquisas com a utilização do laser de Er:YAG (Armengol et al., 2000; Corona et al., 2001; Benjamin, 2002), oferecendo ao paciente menor desconforto e dor durante o ato operatório (Banerjee et al., 2000), buscando a redução desses efeitos indesejados (Burnett et al., 2001).

Devido à ausência de relatos na literatura em relação à sensibilidade dentária e a preferência pelo método de tratamento apresentada por crianças durante a remoção seletiva de lesões de cárie em dentes decíduos utilizando o laser de Er:YAG torna-se fundamental a realização de estudos clínicos que busquem preservar a estrutura dentária remanescente com maior conforto para as crianças. 
2. Proposiçã̃o 


\section{Proposição}

O presente estudo tem por objetivo avaliar a sensibilidade dentária em dentes decíduos durante a remoção seletiva de lesões de cárie e preparo cavitário, empregando o laser de Er:YAG, por meio da escala facial analógica e o método de remoção de tecido cariado preferido pelas crianças. 


\section{Xateriale Xétodo}




\section{MATERIAL e MÉTOdo}

\subsection{Delineamento experimental}

O fator em estudo foi o método empregado para a remoção seletiva de lesões de cárie e preparo cavitário em dois níveis: (I) Laser de Er:YAG (250mJ / 4 Hz) e (II) Método Convencional (turbinas em alta e baixa rotação), ambos associados a curetas. O experimento foi composto por crianças que apresentavam pelo menos 2 lesões de cárie ativas, com cavitação atingindo dentina, localizadas na superfície oclusal (classe I) de molares decíduos homólogos $(n=20)$, de acordo com um delineamento em blocos completos e casualizados. As variáveis de resposta foram a sensibilidade dental analisada durante a remoção seletiva do tecido cariado e preparo cavitário, empregando a escala facial analógica. A preferência pelo método de remoção seletiva do tecido cariado avaliada 7 dias após a realização da restauração.

\subsection{Seleção das Crianças}

Foram examinadas aproximadamente 2800 crianças nas escolas estaduais da cidade de Ribeirão Preto - SP, das quais, 20 foram selecionadas, com idade entre 7 e 10 anos, de ambos os gêneros. O critério de inclusão das crianças foi a presença de pelo menos 2 lesões de cárie ativas com cavitação atingindo dentina localizada na superfície oclusal (Classe I) em molares decíduos homólogos que não haviam sido restaurados anteriormente.

\subsection{Seleção dos dentes}

As crianças selecionadas foram submetidas a exame clínico sob iluminação adequada, na Clínica de Odontopediatria da FORP-USP e receberam instruções de higiene bucal, onde foi realizada profilaxia com pasta de pedra pomes (SS White, Rio de Janeiro, RJ, Brasil) e água. A profilaxia para remoção do biofilme foi realizada com auxílio de taça de borracha (Jon, São Paulo, SP, Brasil) em superfícies lisas, e escova de Robinson (Jon, São Paulo, SP, Brasil), nas superfícies oclusais, ambos conectados ao micromotor (N270, Dabi Atlante, Ribeirão Preto SP, Brasil). Os dentes incluídos na pesquisa foram os molares decíduos homólogos cariados, com resposta positiva ao teste térmico realizado com Endofrost (Roeko, Langenau, Alemanha), apresentando lesões de cárie ativas localizadas na superfície oclusal 
(Classe I), com cavitação atingindo dentina, confirmadas por meio de exame padronizado com radiografias interproximais, utilizando posicionador (Jon, São Paulo, Brasil) e filmes radiográficos Kodak no 2 (Kodak, Nova York, EUA), com exposição de 50 kV, 10 mA, 0,6 segundos (Spectro 70 X, Dabi Atlante, Ribeirão Preto SP). O processamento dos filmes foi realizado automaticamente (A/ T2000 XR, Air Techniques). Foram excluídos da pesquisa os dentes que apresentaram lesões de cárie envolvendo outra superfície além da face oclusal, presença de dor e/ou sensibilidade espontânea, fístula ou edema, mobilidade não compatível com o estágio de rizólise e, ao exame radiográfico, presença de radiolucidez na região de furca e periápice, aumento do espaço periodontal e reabsorção dentária interna / externa.

Após a seleção das crianças, foi apresentado aos pais o termo de consentimento livre e esclarecido (Anexo A), convidando a criança a participar como sujeito da pesquisa, de acordo com a aprovação do Comitê de Ética em Pesquisa da FORP-USP (Anexo B), pelo processo número 2010.1.159.58.3.

Os responsáveis foram informados quanto ao propósito do estudo, e foram dados detalhes sobre o tratamento com laser, incluindo precauções e possíveis efeitos tais como ruídos de estalos e o odor associados com o processo de ablação. Nesse momento também foram preenchidas as fichas de anamnese e odontogramas relativos as condições gerais de saúde e dos dentes de cada criança (Anexo C).

\subsection{Protocolo Clínico}

As crianças selecionadas receberam profilaxia dental conforme descrito anteriormente, aplicação tópica de flúor e instruções de higiene bucal individualmente. Os dentes das crianças que apresentavam necessidade de tratamento e que não foram selecionados para a pesquisa foram tratados na Clínica de Odontopediatria da Faculdade de Odontologia de Ribeirão Preto (FORP-USP), onde foram incluídos procedimentos de adequação do meio bucal e restaurações com resina composta. Os dentes selecionados para a pesquisa foram tratados no laboratório de pesquisa em laser do Departamento de Dentística Restauradora da FORP-USP. As crianças que necessitavam de avaliação ortodôntica foram encaminhadas para a Clínica de Ortodontia dessa mesma instituição. 
Os dentes selecionados para a pesquisa foram submetidos a um sorteio para determinar qual tipo de tratamento seria aplicado: (I) Laser de Er:YAG ou (II) Método Convencional, ambos associados a curetas. O anestésico EMLA (Laboratório Astrazeneca, Cotia SP, Brasil), na quantidade de 0,5 g foi aplicado por meio de haste flexível com ponta de algodão (Cotonete ${ }^{\circledR}$, Johnson \& Johnson, São José dos Campos, SP), nas papilas gengivais dos dentes decíduos de todas as crianças atendidas, a fim de permitir conforto prévio à colocação do grampo utilizado para o isolamento absoluto do campo operatório (Lim; Julliard, 2004). Todos os dentes tratados receberam isolamento absoluto com lençol de borracha (Madeitex, São José dos Campos, SP, Brasil), utilizando grampos de números 26 ou 14 (Duflex, SSWhite, Rio de Janeiro, RJ, Brasil), de acordo com a morfologia dentária de cada molar decíduo. Esses grampos foram inseridos na cavidade bucal com auxilio da pinça porta grampos (Duflex, SSWhite, Rio de Janeiro, RJ, Brasil), com lençol de borracha previamente perfurado e inserido em um porta dique (JON, São Paulo, SP, Brasil), (Croll, 1995). Após a conclusão do isolamento absoluto, foi realizada a remoção seletiva da lesão de cárie, empregando laser de Er:YAG no molar decíduo de um hemi-arco ou método convencional no molar decíduo contralateral, ambos associados a curetas, de acordo com sorteio previamente realizado.

Para o preparo cavitário, acesso a lesão de cárie e remoção seletiva do tecido cariado, no grupo experimental foi utilizado o laser de Er:YAG (Fidelis Er III, Fotona, Ljubljana, Slovenia), utilizando caneta (R02), no modo não-contato, distância focal de $7 \mathrm{~mm}$, energia pulsátil de $250 \mathrm{~mJ}$, frequência de pulsos de $4 \mathrm{~Hz}$ (Krause et al., 2008), spot size de 0,9 mm, densidade de energia de $39 \mathrm{~J} / \mathrm{cm} 2$, com fluxo de água de $6 \mathrm{ml} / \mathrm{min}$, associado à curetas números 111/2, 16 e 18 (Duflex, SSWhite, Rio de Janeiro,RJ, Brasil). No grupo controle, foi realizado a remoção seletiva do tecido cariado pelo método convencional com turbina de alta rotação (Roll Air 3, Kavo, Joinville, SC, Brasil), utilizando pontas esféricas diamantadas números 1012 e 1014 (KG Sorensen, Barueri, SP, Brasil), para remoção do esmalte cavo-superficial e para a remoção seletiva do tecido cariado turbina de baixa rotação (N270, Dabi Atlante, Ribeirão Preto, SP, Brasil), com brocas carbide esféricas números 1/2, 1 e 2 associados à curetas números 1111/2, 16 e 18 (Duflex, SSWhite, Rio de Janeiro, RJ, Brasil). A remoção seletiva do tecido cariado foi realizada na camada superficial de dentina necrótica das paredes circundantes, utilizando laser de Er:YAG ou método convencional, ambos associados à curetas afiadas, onde o tecido cariado foi 
completamente removido das paredes circundantes, e na parede pulpar foi mantida uma camada de dentina afetada, endurecida e seca, resistente à curetagem, com aspecto de lascas ou escamas (Massara et al., 2002; Al Zayer et al., 2003), passível de remineralização (Kidd, 2004; Thompson et al., 2008; Maltz et al., 2012), avaliada de acordo com critérios clínicos de dureza (Maltz et al., 2007).

\subsection{Avaliação da sensibilidade}

Antes do início dos procedimentos para o tratamento odontológico restaurador, as crianças foram instruídas a levantar a mão, como um sinal para que se interrompesse o tratamento no caso de apresentarem qualquer desconforto durante esse período. Os responsáveis que acompanhavam as crianças permaneceram presentes durante todo atendimento e tomaram ciência das instruções se mostrando favoráveis a essa conduta. Neste momento também foi explicado com linguagem simples como a criança poderia indicar a presença de dor ou desconforto na escala facial analógica, exposta em local visível durante todo procedimento.

A escala facial analógica, composta por 4 faces, graduadas conforme a intensidade da dor: sem dor, dor média, dor moderada e dor severa (Liu et al., 2006), confeccionada com figuras traçadas na cor preta, em papel branco, de $10 \mathrm{~cm}$ de largura por $28 \mathrm{~cm}$ de comprimento, para manter parâmetro de fundo e tamanho consistentes (figura 1), foi apresentada as crianças sem nenhuma descrição visual ou numérica.

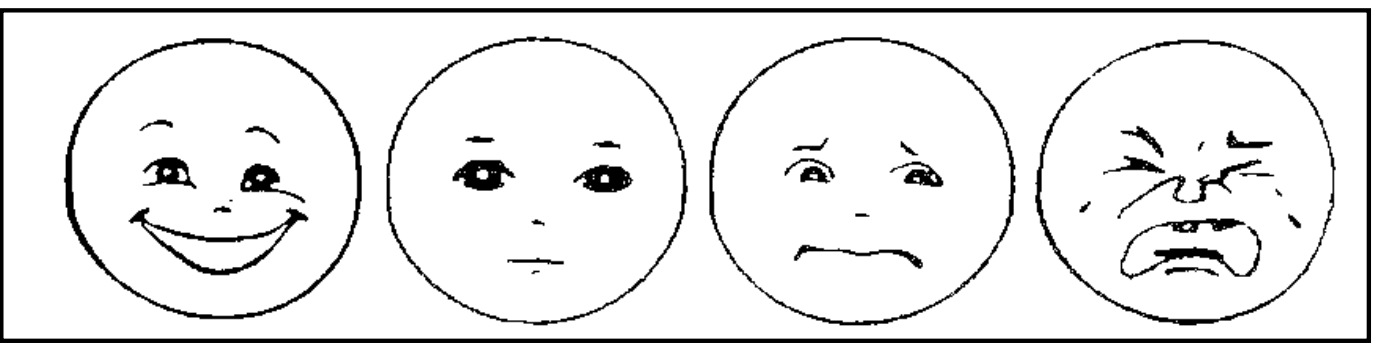

Figura 1. Escala Facial Analógica.

\subsection{Tratamento Restaurador}

Para a seleção da cor da resina composta Filtek Supreme (3M ESPE, São Paulo, SP, Brasil), nanoparticulada foi empregada à escala de cores Vita (Vita 3D, 
Wilcos do Brasil Indústria e Comércio Ltda, Petrópolis, RJ, Brasil), antes da realização do isolamento absoluto.

Após a remoção seletiva das lesões de cárie, nas cavidades médias foi realizada proteção pulpar indireta com cimento de ionômero de vidro (Ketac Molar 3M, São Paulo, SP, Brasil), e nas cavidades profundas, foi realizada proteção pulpar indireta utilizando cimento de hidróxido de cálcio (Dycal, Dentisply Indústria e Comércio Ltda, Petrópolis, RJ, Brasil) e cimento de ionômero de vidro (Ketac Molar 3M, São Paulo, Brasil), seguido da aplicação de ácido fosfórico 37\% por 15 segundos em esmalte e 7 segundos em dentina (Van Meerbeek et al., 1994), lavagem da cavidade com água durante 1 minuto, remoção do excesso de água com cânula de sucção e posterior secagem da cavidade com bolinhas de algodão. O sistema adesivo (Adper Single Bond 2, 3M ESPE, São Paulo, SP, Brasil), foi aplicado em duas camadas com aplicador descartável (KGBrush, KG Sorensen, Cotia, SP, Brasil), intercaladas por um jato de ar por 5 segundos, e fotopolimerizado (XL 3000, Jeltrate Chromatic, Dentsply Indústria e Comércio Ltda, Petrópolis, RJ, Brasil), seguindo instruções do fabricante. Para a restauração foi aplicada resina composta (Filtek Supreme, 3M ESPE, São Paulo SP, Brasil) em pequenos incrementos com espátula para resina, fotopolimerizados por 20 segundos, devolvendo a forma anatômica aos dentes.

Terminada a restauração, foi removido o isolamento absoluto e realizado ajuste oclusal com papel carbono (AccuFilm, Parkell, Farmingdale, NY, EUA), e pontas diamantadas para acabamento (KG Sorensen, Cotia, SP, Brasil). As crianças retornaram após sete dias, para polimento final da restauração com pontas abrasivas (Enhance, Dentisply Indústria e Comércio Ltda, Petrópolis, RJ, Brasil). A figura 2 representa o desenho esquemático da metodologia empregada.

\subsection{Avaliação da Preferência pelo Tratamento}

Após 7 dias da realização das restaurações, as crianças retornaram ao Laboratório de Laser do Departamento de Dentística da FORP-USP e relataram a sua preferência quanto ao método de tratamento utilizado por meio da pergunta: Caso você precise tratar um dente novamente, o que você irá preferir: laser ou motor? (Mosskull; Bagesund, 2012) 
Laser de Er:YAG

Convencional
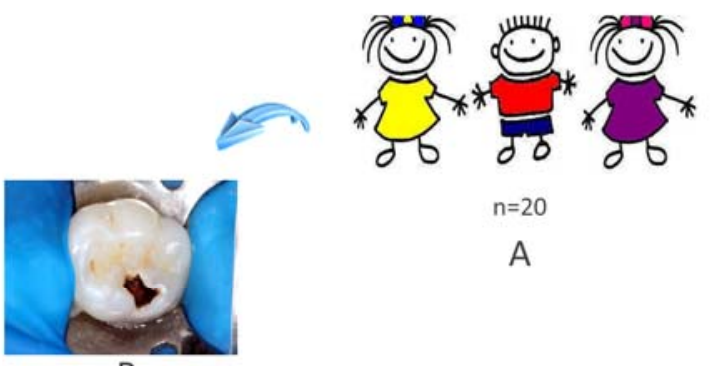

A

B

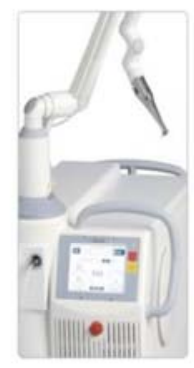

D

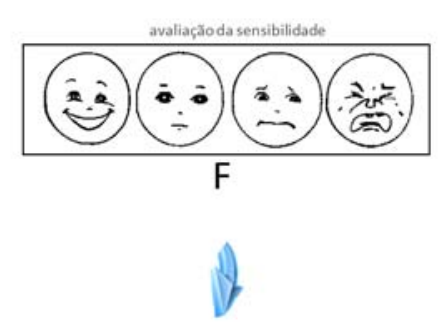

G

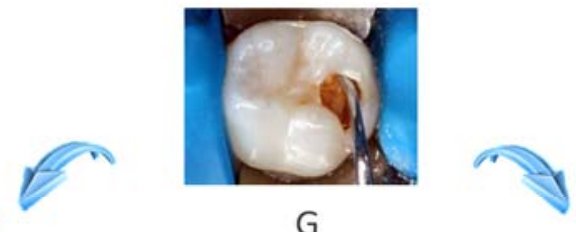

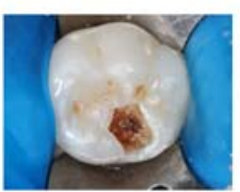

H
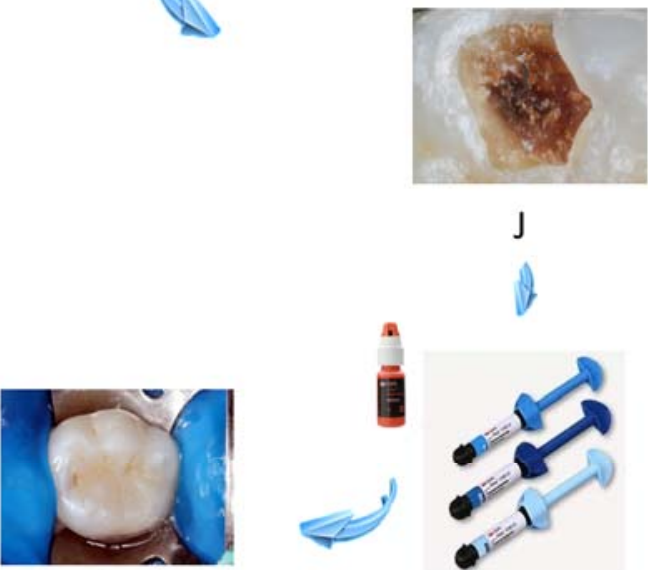

L
J

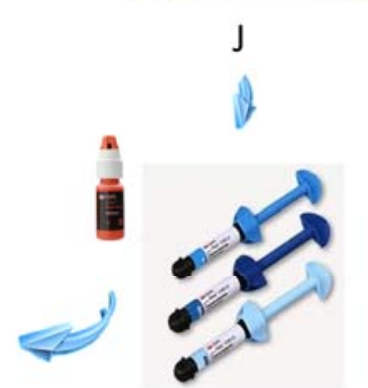

K
C

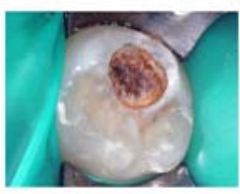

I

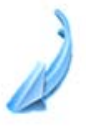

E
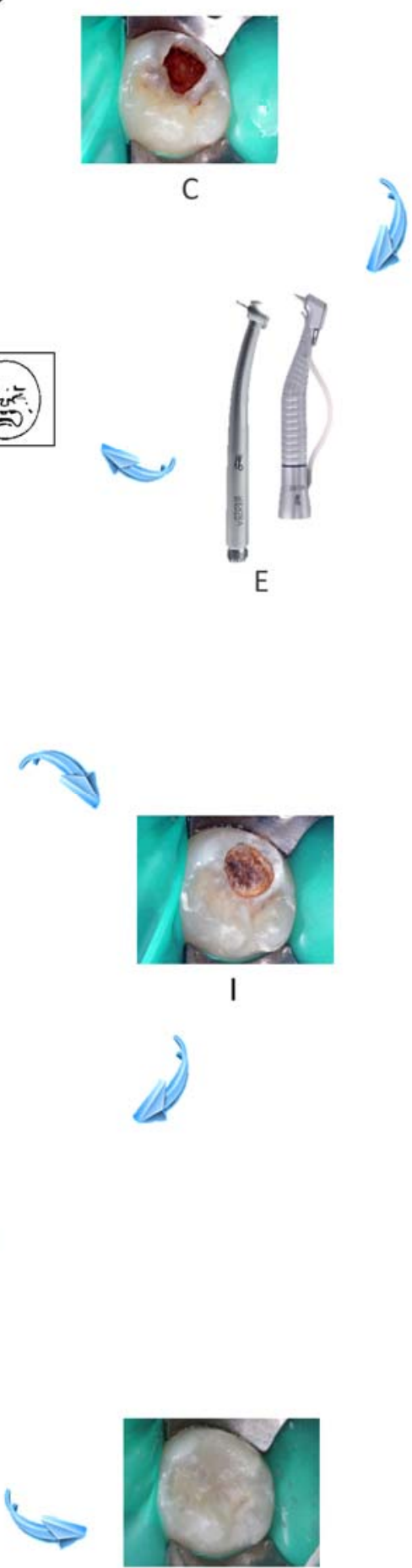

M

Figura 2: A- crianças ( $\mathrm{n}=20$ ); B-Cárie oclusal (Grupo I); C-Cárie Oclusal (Grupo II); D-Laser de Er:YAG (250 mJ/4Hz); E-Método Convencional (Turbinas de alta e baixa rotação); F-Escala facial analógica; G- complementação da remoção seletiva de lesões de cárie com curetas; H-Remoção seletiva de lesões de cárie (Grupo I); I- Remoção seletiva de lesões de cárie (Grupo II); J- Avaliação visual e tátil da dentina afetada ou infectada ; K- Adper Single Bond 2 / Filtek Z350 XT (3M); L- Restauração da cavidade (Grupo I); M- Restauração da cavidade (Grupo II). 


\subsection{Análise Estatística}

Os dados obtidos durante a remoção seletiva de lesões de cárie em dentes decíduos para avaliação da sensibilidade dentária foram analisados pelo método de tabela de contingência com teste exato de Fisher (tratamento versus face indicada), utilizando o software STATA® 12 para Windows (StataCorp LP, Texas, USA). A preferência pelo método de remoção seletiva das lesões de cárie em dentes decíduos foi avaliada por meio da tabela descritiva. 
4. Resultados 


\section{Resultados}

O teste de Fischer não indicou associação entre o método experimental e a face indicada pela criança $(p=0,065)$, como mostra a tabela 1 .

Tabela 1. Distribuição de frequência do tratamento experimental e a face indicada pela criança

\begin{tabular}{cccccc}
\hline Face & $\mathbf{1}$ & $\mathbf{2}$ & $\mathbf{3}$ & $\mathbf{4}$ & Total \\
\hline Método Convencional & 7 & 5 & 6 & 2 & 20 \\
\hline Laser de Er:YAG & 10 & 9 & 1 & 0 & 20 \\
\hline Total & 17 & 14 & 7 & 2 & 40
\end{tabular}

Pearson chi2(3) $=7.2437 \mathrm{Pr}=0.065$

Fisher's exact $=0.065$

O gráfico 1 representa o número de crianças em relação as faces indicadas e métodos de remoção seletiva de lesões de cárie utilizados.

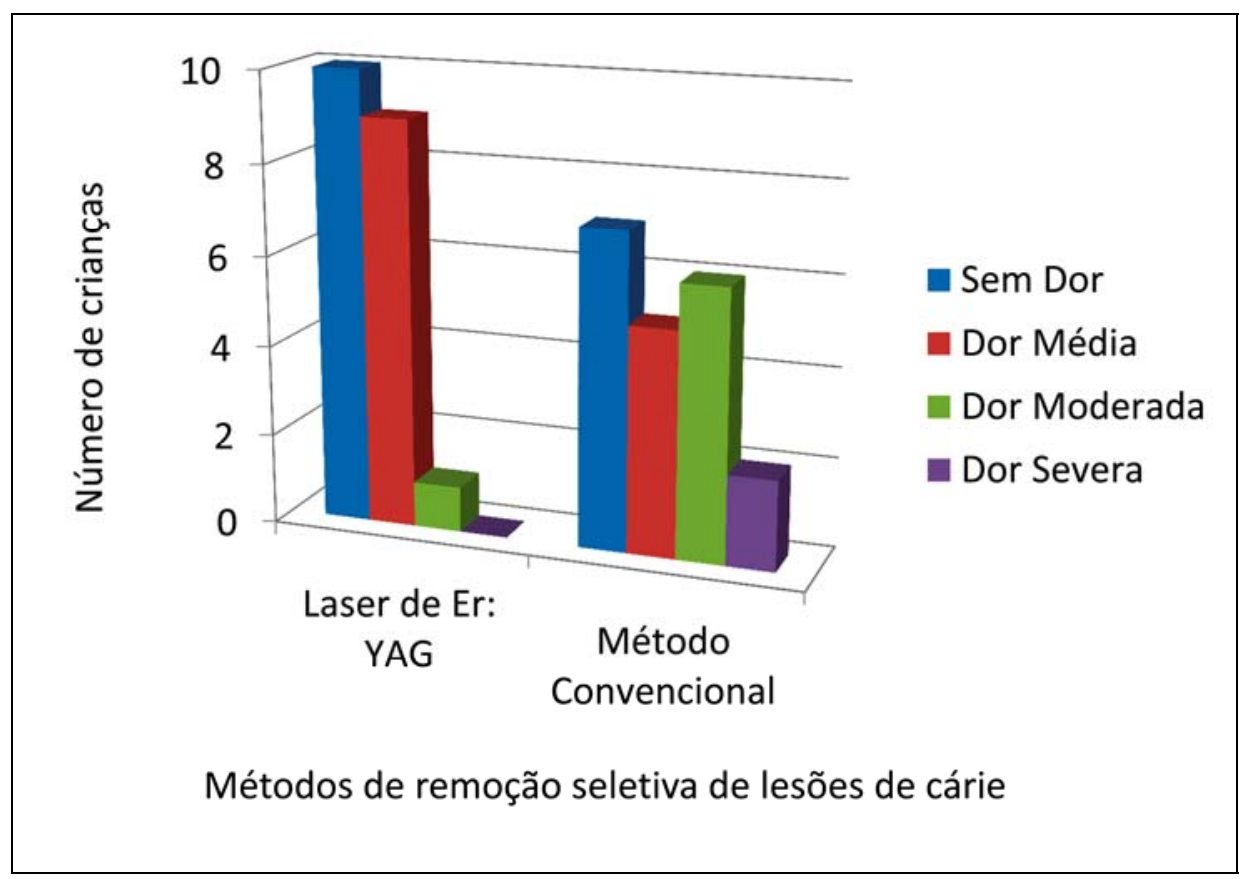

Gráfico 1. Diagrama de barras do número de crianças em relação às faces indicadas e métodos de remoção de lesões de cárie utilizados. 
A tabela 2 ilustra a preferência das crianças pelo uso do Laser de Er:YAG em um tratamento restaurador futuro.

Tabela 2. Número de crianças em relação à preferência pelo método de remoção seletiva de lesões de cárie

\begin{tabular}{cc}
\hline Método & $\mathbf{N}^{\circ}$ de crianças \\
\hline Laser de Er:YAG & 18 \\
\hline Convencional & 01 \\
\hline Sem preferência & 01 \\
\hline
\end{tabular}

O gráfico 2 representa a porcentagem das crianças em relação à preferência pelo método de remoção seletiva de lesões de cárie.

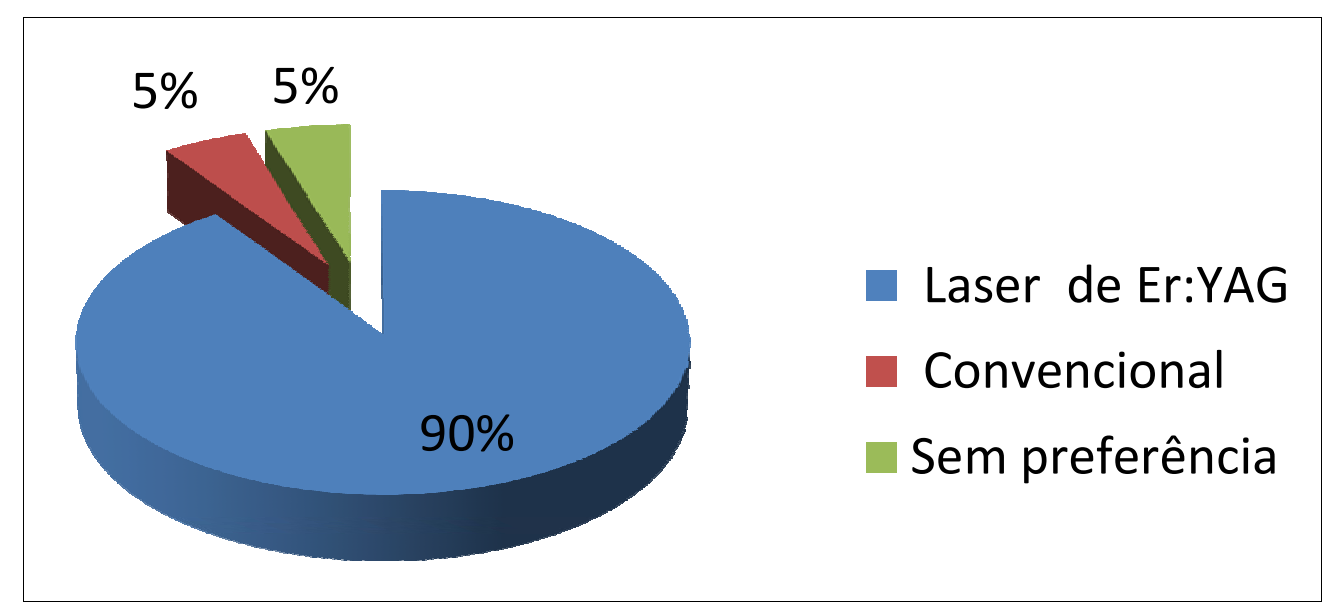

Gráfico 2. Diagrama circular da porcentagem das crianças em relação à preferência pelo método de remoção seletiva de lesões de cárie 
5. Discussão 


\section{DıSCUSSÃo}

A remoção seletiva de tecido dentário cariado em dentes decíduos (Falster et al., 2002; Pinto et al., 2006; Franzon et al., 2007; Lula et al., 2009) e permanentes (Mertz-Fairhurst et al., 1998; Maltz et al., 2002; Kidd, 2004; Bjornal et al., 2010, Banerjee, 2013), tem como vantagens remover o mínimo possível de estrutura dentária remanescente sadia, evitando exposições pulpares (Ricketts et al., 2006; Thompson et al., 2008), principalmente em dentes decíduos que apresentam menor porção mineral (De Menezes Oliveira et al., 2010), uma vez que, a dentina afetada que permanece na parede pulpar da cavidade preparada é passível de remineralização (Kidd, 2004; Maltz et al., 2007; Thompson et al., 2008; Maltz et al., 2012). Aliado a esse fato, e as inúmeras vantagens do uso do laser de Er:YAG na remoção de tecido cariado, dentre elas, a diminuição da vibração, pressão e ruído, (Keller; Hibst ,1998; Kumazaki, 1998; Cozean et al., 1997; Evans et al., 1998) fatores esses que causam maior ansiedade e medo ao paciente e a diminuição da necessidade do uso de anestesia local, (Liu et al.,2006; Krause et al., 2008), a utilização do laser de Er:YAG torna o tratamento odontológico menos traumático (Keller; Hibst,1998) e preferido pelos pacientes (Liu et al., 2006; Mosskull et al., 2012).

Os resultados desse estudo mostraram que não houve diferença estatisticamente significante entre os tratamentos realizados com o laser de Er:YAG e método convencional na avaliação da sensibilidade dentária durante a remoção seletiva de lesões de cárie em dentes decíduos. Esses resultados podem ser justificados devido ao cuidado em se remover apenas a porção de dentina necrosada e desorganizada, (Kidd, 2004), preservando ao máximo a estrutura dentaria remanescente sadia, especialmente a porção de dentina esclerótica que protege a polpa das agressões e estímulos álgicos (Stanley et al.,1983), sofridos pelo elemento dentário durante o processo de cárie. O grau de desconforto máximo da escala facial analógica foi relatado por 2 crianças ao término da remoção seletiva do tecido cariado utilizando o método convencional, resultados esses, que concordam com o estudo de Liu et al.(2006), onde 6 crianças relataram desconforto máximo durante a remoção total de lesões de cárie utilizando o método convencional. 
Os preparos cavitários utilizando o laser de Er:YAG apresentaram-se mais confortáveis e conservadores que os realizados com os métodos convencionais (turbinas em alta e baixa rotação), devido ao fato do laser possuir uma vantagem distinta em relação ao uso de pontas diamantadas e brocas, permitindo ao profissional uma maior distinção entre os sons característicos durante a ablação dos tecidos (Pelagalli et al., 1997), proporcionando a diferenciação entre o tecido cariado e a dentina e esmalte sadios, resultando na remoção apenas das porções necróticas do tecido cariado, que apresentam maior umidade (Aoki et al., 1998) e sofrem portanto uma ablação mais eficiente (Keller; Hibst, 1997), diferindo do uso de brocas e pontas diamantadas, que também em razão do seu formato, acabam removendo maior quantidade de tecido dentário sadio. O laser de Er:YAG promove uma remoção de tecido dentário mais seletiva (Pelagalli et al.,1997) e proporciona um maior controle por parte do operador, produzindo preparos cavitários mais conservadores (Peters et al., 2001; Brostek et al., 2006), especialmente em dentes decíduos que apresentam a camada de esmalte e dentina mais delgadas (Mortimer, 1970), maior volume da câmara pulpar, com cornos pulpares bem pronunciados em relação aos dentes permanentes, o que poderia facilitar a sensação de dor ou desconforto ou até exposição pulpar acidental durante a remoção total do tecido cariado. Os resultados deste estudo confirmam os achados de Krause et al., 2008 que mesmo removendo completamente a lesão de cárie em dentes decíduos utilizando o laser de Er:YAG, observaram grande conforto para os pacientes.

O uso do laser de Er:YAG durante a remoção seletiva de lesões de cárie e os preparos cavitários realizados nesse estudo, mostrou-se como uma novidade para as crianças e foi o método preferido por $90 \%$ delas, que justificaram essa preferência por não haver o ruído e a vibração característicos dos métodos convencionais, o mesmo foi observado por Liu et al. (2006) e Mosskull; Bagefund, (2012). As crianças relataram sua satisfação com a eliminação do desconforto produzido pelo ruído dos instrumentos rotatórios, sentiram-se seguras e tranquilas, fato que pode ser comprovado pela realização de todos os procedimentos sem a necessidade de anestesia local infiltrativa, o mesmo observado nos estudos de Krause et al. (2008), que não utilizaram técnicas anestésicas na realização da remoção de lesões de cárie utilizando o laser de Er:YAG em dentes decíduos.

A adaptação das crianças frente ao tratamento odontológico foi comprovada pela realização dos procedimentos restauradores sem o uso de anestesia local 
infiltrativa, sendo apenas utilizado o anestésico EMLA® (Astra Pharmaceuticals, Wayne, USA), que tem a função de bloquear a transmissão do sinal nervoso nos terminais sensoriais, sendo eficaz em tecidos de superfície $(2-3 \mathrm{~mm}$ de profundidade) como as papilas gengivais (Barcohana; Duperon; Yashar, 2003).

No que diz respeito à dor, as crianças envolvidas neste estudo não se queixaram diretamente de manifestações dolorosas, mas sim de incômodos e desconfortos na remoção seletiva do tecido cariado, de forma mais evidentes relacionados ao ruído e a vibração produzidos pelo uso dos instrumentos rotatórios convencionais, especialmente o de baixa rotação que produziu maior vibração, o mesmo foi observado por Cozean et al. (1997); Keller et al. (1998); Matsumoto et al. (1998); Liu et al. (2006), onde os pacientes relataram menor desconforto durante a utilização do laser de Er:YAG na remoção total do tecido cariado, desta forma, o laser de Er:YAG pode ser usado como um método de remoção seletiva do tecido cariado em dentes decíduos, pois estabelece padrões superiores de conforto para os pacientes em relação ao método convencional, sem causar nenhum dano às estruturas dentárias adjacentes, desde que se utilizem parâmetros seguros de irradiação, conforme empregados nesse estudo.

A compreensão das reações emocionais infantis, bem como das sensações de medo e dor através dos tratamentos realizados nos dentes decíduos utilizando o laser de Er:YAG e o método convencional nesse estudo, com o auxílio da escala facial analógica proposta por Liu et al. (2006) foi de fácil compreensão e as crianças se sentiram seguras em poder descrever o que estavam sentindo durante a remoção seletiva de tecido cariado. A escala facial analógica utilizada forneceu resultados seguros e precisos, e este tipo de avaliação têm sido comumente empregado para aferir diferentes aspectos subjetivos de humor (Barton et al., 1993), dor (Campbell; Lewis, 1990) e particularmente ansiedade (Kidson; Hornblow, 1982), permitindo a avaliação do estado emocional em pacientes submetidos a situações diversas de dor (Coulthard; Rood, 1993; Buckelew et al., 1992), como nos procedimentos odontológicos e cirúrgicos (Moore, 1991, Hosey; Blinkhorn, 1995; Liu et al., 2006; Facco et al., 2011), tendo indicação para mensuração álgica em crianças maiores de 4 anos, frente às diferentes terapias de intervenção odontológicas (Abreu et al., 2011). Essas escalas faciais não dependem necessariamente de descrições verbais, podendo ser facilmente adotadas pelos dentistas durante 0 tratamento 
odontopediátrico, uma vez que são bem compreendidas pelas crianças, auxiliando na mensuração de suas reações emocionais.

Diante do exposto, a utilização do laser de Er:YAG foi o método preferido pelas crianças, preservando o máximo possível da estrutura dentária remanescente sadia com menor ruído, pressão e vibração, embora não tenha alterado a avaliação da sensibilidade dentária durante a remoção seletiva de lesões de cárie em dentes decíduos. Desse modo, devemos considerar a necessidade de realização de novos estudos científicos sobre as aplicações clínicas do laser de Er:YAG para a realização de remoção seletiva de lesões de cárie. 


\section{Conclusão}




\section{Conclusão}

Considerando a metodologia utilizada e os resultados obtidos pode-se concluir que independente do método utilizado, convencional ou laser de Er:YAG, a sensibilidade dentária não foi alterada durante a remoção seletiva de lesões de cárie, no entanto, o laser foi o método preferido pela grande maioria das crianças. 


\section{Referências Bibliográficas"}




\section{REFERÊNCIAS BIBLIOGRÁFICAS}

Abreu DM, Leal SC, Frencken JE. Pain experience after conventional, a traumatic, and ultraconservative restorative treatments in 6- to 7-yr-old children. Eur J Oral Sci. 2011;119:163-8.

Al-Zayer MA, Straffon LH, Feigal RJ, Welch KB. Indirect pulp treatment of primary posterior teeth: a retrospective study. Operative Dent. 2003 Jan-Feb;25(1):29-6.

Aoki A, Ishikawa I, Yamada T, Otsuki M, Watanabe H, Tagami J, et al. Comparison between Er:YAG laser and conventional technique for root caries treatment in vitro. J Dent Res. 1998;77(6):1404-14.

Armengol $\mathrm{V}$, Jean A, Marion D. Temperature rise during Er:YAG and Nd:YAP laser ablation of dentin. J Endod. 2000;26(3):138-41.

Banerjee A, Kidd EA, Watson TF. In vitro evaluation of five alternative methods of carious dentine excavation. Caries Res. 2000;34(2):144-50.

Banerjee A. Minimal intervention dentistry: part 7. Minimally invasive operative caries management: rationale and techniques. Br Dent J. 2013 Feb;214(3):107-11.

Barcohana N, Duperon DF, Yashar M. The relatyionship pf apllication time to EMLA efficacy.J Dent Child (Chic). 2003 Jan-Apr;70(1):51-4.

Barton CD Jr, Dufer D, Monderer R, Cohen MJ, Fuller, HJ , Clark MR, De Paulo JR. Mood variability in normal subjects on lithium. Biol Psychiatr. 1993;34:878-4.

Benjamin SD. Dental laser: part 3. Use of dental lasers on hard tissue. Pract Proced Aesthet Dent. 2002;14(5):422-4.

Bjorndal L, Larsen T, Thylstrup A. A clinical and microbiological study of deep carious lesions during stepwise excavation using long treatment intervals. Caries Res. 1997;31:411-7.

Bjorndal L, Larsen T. Changes in the cultivable flora in deep carious lesions following a stepwise excavation procedure. Caries Res. 2000;34:502-8.

Bozaijs WG, Marshal GW, Cooley RO. Mechanicalpretreatments and etctllng of primary-tooth enamel. J Dent Child. 1979;(46):43-9.

Brostek AM, Bochenek AJ, Walsh LJ. Minimally invasive dentistry: a review and update. Shanghai Kou Qiang Yi Xue. 2006 Jun, 15(3) 225-49.

Buckelew SP, Conway RC, Shutty MS, Lawrence JA, Grafing MR, Anderson SK, et al. Spontaneous coping strategies to manage acute pain and anxiety during electrodiagnostic studies. Arch Phys Med Rehabil. 1992 Jun;73(6):594-8. 
Buckelew SP, Conway RC, Shutty MS, Lawrence JA, Grafing MR, Anderson SK, et al. Spontaneous coping strategies to manage acute pain and anxiety during electrodiagnostic studies. Arch Phys Med Rehabil. 1992 Jun;73(6):594-8.

Burnett LH, Conceição EN, Pelino JE, Eduardo CP. Comparative study of influence on tensile bond strength of a composite to dentin using Er:YAG laser, air abrasion, or air turbine for preparation of cavities. J Clin Laser Med Surg. 2001;19(4):199-202.

Campbell WI, Lewis S. Visual analogue measurement of pain. Ulster Med J. 1990;59:149-54.

Cederlund A, Lindskog S, Blomlöf J. Effect of chemo-mechanical caries removal

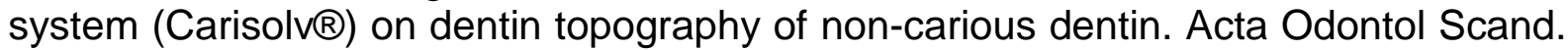
1999;57(4):185-9.

Chapman HR, Kirby-Tumer NC. Dental fear in children- a proposed model. Br Dent J 2000;187(8):175-80.

Corona SAM, Borsatto MC, Palma-Dibb RG, Ramos RP Jr, Brugnera A, Pécora JD. Microleakage of class $\mathrm{V}$ resin composite restorations after bur, Air-abrasion or Er:YAG laser preparition. Oper Dent. 2001;26(5):491-7.

Coulthard P, Rood JP. Anxiety measures during induced experimental pain. Anesth Pain Control Dent. 1993;2:150-3.

Cozean C, Arcoria CJ, Pelagalli J, Powel MGL. Dentistry for the 21th century? Erbuim: YAG laser forteeth. J Am Dent Assoc. 1997;128(8):1080-7.

Croll TP. Restorative dentistry for preschool children. Dent Clin North Am. 1995 Oct;39(4):737-70.

De Menezes Oliveira MAH, Torres CP, Gomes-Silva JM, Chinelatti MA, De Menezes $\mathrm{FCH}$, Palma-Dibb RG, et al. Microstructure and mineral composition of dental enamel of permanent and deciduous teeth. Microsc Res Tech. 2010;73:572-7.

Dommisch H, Peus K, Kneist S, Krause F, Braun A, Hedderich J et al..Fluorescencecontrolled Er:YAG laser for caries removal in permanent teeth: a randomized clinical trial.Eur J Oral Sci. 2008;116(2):170-6.

Dostálová $T$, Jelínková $H$, Kucerová $H$, Krejsa $O$, Hamal $K$, Kubelka J, et al. Noncontact Er: YAG laser ablation: clinical aluation. J Clin Laser Med Surg. 1998;16(5):273-82.

Duque C, Negrini TC, Sacono NT, Spolidorio DM, De Souza Costa CA, Hebling J. Clinical and microbiological performance of resin-modified glass-ionomer liners after incomplete dentine caries removal. Clin Oral Investig. 2009;13:465-71. 
Eduardo PLP, Ramos ACB, Eduardo CP. The use of the Er:YAG laser in cavity preparation-Clinical cases. Proceedings of the $6^{\text {th }}$ International Congress on Lasers in Dentistry; 1998; Maui, Hawaii; 1998. p. 62.

Evans DJ, Mathews S, Pitts NB. A clinical evaluation of an erbium:YAG laser ablation: a preliminary evaluation of human teeth. J Clin Laser Med Surg. 2000;15:117-21.

Facco E, Zanette G, Favero L, Bacci C, Sivolella S, Cavallin F, Manani G. Toward the validation of visual analogue scale for anxiety. Anesth Prog. 2011;58:8-13.

Falster CA, Araujo FB, Straffon LH, Nör JE. Indirect pulp treatment: in vivo outcomes of an adhesive resin system vs calcium hydroxide for protection of the dentin-pulp complex. Pediatr Dent. 2002;24(3):241-8.

Franzon R, Casagrande L, Pinto AS, García-Godoy F, Maltz M, de Araujo FB. Clinical and radiographic evaluation of indirect pulp treatment in primary molars: 36 months follow-up. J Am Dent. 2007 Jun;20(3):189-92.

Freitas PM, Navarro RS, Barros JA, De Paula Eduardo C. The use of Er:YAG laser for cavity preparation: an SEM evaluation. Microsc Res Tech. 2007 Sep;70(9):803-8.

Fusayama T. Two layers of carious dentin; diagnosis and treatment. Oper Dent. 1979;4(2):63-70.

Green RM, Green A. Adult attitudes to dentistry among dental attenders. Br Dent J. 1985;159(5) 157-160.

Hibst R, Keller U. Experimental studies of the application of the Er:YAG laser on dental hard subs-tances: I. Measurement of the ablation rate. Lasers Surg Med. 1989; 9:338-4.

Hirayama A, Yamada M, Miake K. An electron microscopic study on dentinal tubules of human deciduous teeth. Shikwa Gahuko. 1986;86(6):1021-31.

Hosey MT, Blinkhorn AS. An evaluation of four methods of assessing the behaviour of anxious child dental patients. Int J Dent Paediatr. 1995;5:87-95.

Hosoya $\mathrm{Y}$. The effect of acid etchingtimes on ground primary enamel. J Clin Ped Dent .1991;(15):188-4.

Hossain M, Nakamura Y, Tamaki Y, Yamada Y, Murakami Y, Matsumoto K. Atomic analysis and knoop hardness measurement of the cavity floor prepared by Er,Cr:YSGG laser irradiation in vitro. J Oral Rehabil. 2003 May;30(5):515-21.

Hugo B, Stassinakis A. Preparation and restoration of small interproximal carious lesions with sonic instruments. Pract Periodont Aesthet Dent. 1998;10(3):353-9.

Jacobson B, Asgari A. Restorative dentistry for children using a hard tissue laser. Alpha Omegan. 2008;101(3):133-9. 
Kato J, Moriya K, Jayawardena JA, Wijeyeweera RL. Clinical application of Er:YAG laser for cavity preparation in children. J Clin Laser Med Surg. 2003;21:151-5.

Keller U, Hibst R. Effects of Er:YAG Laser in caries treatment: a clinical pilot study. Lasers Surg Med. 1997;20:32-8.

Keller U, Hibst R, Geurtsen W, Schilke R, Heidemann D, Klaiber B, et al. Erbium: YAG laser application in caries therapy. Evaluation of patient perception and acceptance. J Dent. 1998;26(8):649-56.

Kidd EAM. How clean must a cavity be before restoration? Caries Res. 2004;38:30513.

Kidson M, Hornblow A. Examination anxiety in medical students: experiences with the visual analogue scale for anxiety. Med Educ.1982;16:247-50.

Kornblit R, Trapani D, Bossù M, Muller-Bolla M, Rocca JP, Polimeni A. The use of Erbium:YAG laser for caries removal in paediatric patients following MinimallyInvasive Dentistry concepts. Eur J Paediatr Dent. 2008 Jun;9(2):81-7.

Krause F, Braun A, Lotz G, Kneist S, Jepsen S, Eberhard J. Evaluation of selective caries removal in deciduous teeth by a fluorescence feedback-controlled Er: YAG laser in vivo. Clin Oral Invest. 2008;12:209-15.

Kusaka T, Ishimaru K, Takamizu M, Kohno A. Microleakage of cavities prepared by Er:YAG laser. Proceedings of the 6th International Congress on Lasers in Dentistry; 1998; Maui, Hawaii;1998. p. 187-8.

Lim S, Julliard K. Evaluating the efficacy of EMLA topical anesthetic in sealant placement with rubber dam. Pediatr Dent. 2004;26(6):497-500.

Liu JF, Lai YL, Shu WY, Lee SY. Acceptance and efficiency of Er: YAG laser for cavity preparation in children. Photomed Laser Surg. 2006;24(4):489-93.

Lizarelli RF, Moryiama LT, Bagnato VS. Ablation of composite resins using Er:YAG laser-comparison with enamel and dentin. Lasers Surg Med. 2003;33:132-9.

Low IM, Duraman N, Mahmood U. Mapping the structure, composition and mechanical properties of human teeth. Mater Sci Eng C.2008;28:243-7.

Lula CE, Monteiro-Neto V, Alves CM, Ribeiro CC. Microbiological analysis after complete or partial removal of carious dentin in primary teeth: a randomized clinical trial. Caries Res. 2009;43(5):354-8.

Maltz M, de Oliveira EF, Fontanella V, Bianchi R. A clinical, microbiologic, and radiographic study of deep caries lesions after incomplete caries removal. Quintessence Int. 2002;33(2):151-9. 
Maltz M, Oliveira EF, Fontanella V, Carminatti G. Deep caries lesions after incomplete dentine caries removal: 40-month follow-up study. Caries Res. 2007;41(6):493-6.

Massara Ml, Alves JB, Brandao PR. A traumatic restorative treatment: clinical,ultrastructural and chemical analysis. Caries Res. 2002;36:430-6.

Matsumoto K. Laser treatment for hard tissue. Proceedings of the International Congress on Laser in Dentistry; 1998; Maui, Hawaii. 1998. p. 14.

Mertz-Fairhurst EJ, Curtis JW Jr, Ergle JW, Rueggeberg FA, Adair SM. Ultraconservative and cariostatic sealed restorations: results at year 10 . J Am Dent Assoc. 1998;(1):55-66.

Moore R. Dental fear treatment: comparison of a video training procedure and clinical rehearsals. Scand J Dent Res.1991;99:229-35.

Mortimer KV. The relationship of deciduous enamel structure of dental disease. Caries Res 1970;4:206-223.

Mosskull HP, Bågesund M. Er:YAG laser or high-speed bur for cavity preparation in adolescents. Acta Odontol Scand. 2012. [Epub ahead of print].

Oliveira DC, Manhães LA, Marques MM, Matos AB. Microtensile bond strength analysis of different adhesive systems and dentin prepared with high-speed and Er:YAG laser: a comparative study. Photomed Laser Surg. 2005 Apr;23(2):219-24.

Paddick JS, Brailsford SR, Kidd EA, Beighton D. Phenotypic and genotypic selection of microbiota surviving under dental restorations. Appl Environ Microbiol. 2005;71:2467-72.

Paghdiwala AF. Does the laser work on hard dental tissue? JADA. 1991;122:79-80

Pelagalli J, Gimbel C B, Hansen Rt, Swett A, Winn, D W. Investigational study of the use of EnYAG laser versus dental drill for caries removal and cavity preparationPhase I. J. Clin, Laser Med. Surg., 15(3):109-15,1997.

Peters MC, McLean ME. Minimally invasive operative care. I. Minimal intervention and concepts for minimally invasive cavity preparations. J Adhes Dent. 2001. 3(1) 716. Review

Pinto AS, De Araujo FB, Franzon R, Figueiredo MC, Henz S, Garcia-Godoy F, et al. Clinical and microbiological effect of calcium hydroxide protection in indirect pulp capping in primary teeth. Am J Dent. 2006;19:382-6.

Ricketts DN, Kidd EA, Innes N, Clarkson J. Complete or ultraconservative removal of decayed tissue in unfilled teeth. Cochrane Database Syst Rev. 2006;(3):CD003808.

Sazak H, Türkmen C, Günday M. Effects of Nd: YAG laser, air-abrasion and acidetchin on human enamel and dentin. Oper Dent. 2001;26(5):476-81. 
Stanley HR, Pereira JC, Spiegel E, Broom C, Schultz M. The detection and prevalence of reactive and physiologic sclerotic dentin, reparative dentin and dead tracts beneath various types of dental lesions according to tooth surface and age. $\mathrm{J}$ Oral Pathol. 1983;12(4):257-89.

Sumikawa DA, Marshall GW, Gee L, Marshall SJ. Microstructure of primary tooth dentin. Pediatr Dent. 1999;21(7):439-44.

Takamori K, Furukawa H, Morikawa Y, Katayama T, Watanabe S. Basic study on vibrations during tooth preparations caused by high-speed drilling and Er:YAG laser irradiation. S.Lasers Surg Med. 2003;32(1):25-31.

Thompson V, Craig RG, Curro FA, Green WS, Ship JA. Treatment of deep carious lesions by complete excavation or partial removal: a critical review. J Am Dent Assoc. 2008;139(6):705-12.

Townend E, Dimigen G, Fung D. A clinical study of child dental anxiety. Behav Res Ther. 2000;38(1):31-46.

Tyas MJ, Anusavice KJ, Frencken JE, Mount GJ. Minimal intervention dentistry-a review. FDI Commission Project 1-97. Int Dent J. 2000;50(1):1-12.

Thylstrup A. Caries: summary observations of applied knowledge in view of new knowledge. Tandlaegebladet. 1988;92(2):47-59.

Van Meerbeek B, Peumans M, Verschueren M, Gladys S, Braem M, Lambrechts P, et al. Clinical status of ten dentin adhesive systems. J Dent Res. 1994 Nov;73(11):1690-702.

Wambier DS, Dos Santos FA, Guedes-Pinto AC, Jaeger RG, Simionato MR. Ultrastructural and microbiological analysis of the dentin layers affected by caries lesions in primary molars treated by minimal intervention. Pediatr Dent. 2007;29:22834. 
Alnexos 


\section{ANEXO A}

\section{TERMO DE CONSENTIMENTO LIVRE E ESCLARECIDO}

Nós, Silvana Aparecida Fernandes Polizeli, Rodrigo Alexandre Valério, Profa. Dra. Silmara Aparecida Milori Corona, Profa . Dra. Maria Cristina Borsatto, Profa ${ }^{2}$ Dra. Mônica Campos Serra, Prof. Dr. Antonio Luiz Rodrigues Júnior convidamos o estudante:

RG: , sob responsabilidade de RG:

a participar como voluntário da pesquisa "Estudo in vivo do laser de Er:YAG em dentes decíduos. Análise da sensibilidade dentária, eficácia e eficiência na remoção de lesões de cárie, avaliação microbiológica das cavidades preparadas e das restauracões realizadas."

Esta pesquisa vai avaliar se o laser remove a cárie com a mesma capacidade que o "motorzinho", sendo que estudos relatam que os pacientes sentem menos dor quando removemos a cárie com o laser. O laser é uma luz, que não faz ruído ou vibração, e quando bate no dente, remove a cárie. Muitas pessoas deixam de ir ao dentista por sentirem medo do "motorzinho", mas foram feitos estudos que mostraram que as crianças preferem o laser para remover a cárie porque não dói. As crianças serão avisadas antes do tratamento com o laser sobre os possíveis barulhos de estalos (barulho de pipoca) e o possível cheiro que estão associados ao tratamento.

O dentista fará limpeza de todos os dentes, e todo tratamento restaurador (obturação), além disso, será realizado todo o tratamento que for necessário para que a saúde da boca do voluntário seja atingida. Para termos certeza que o dente está cariado, antes de começarmos vamos tirar raio-x dos dentes. Depois, a cárie vai ser tirada parcialmente pelo "motorzinho", ou pelo laser. Quando o dentista estiver tirando a cárie com o laser ou o "motorzinho", vamos contar o tempo com um cronômetro e usaremos uma cureta (colherzinha), para avaliar se a cárie saiu do dente ou não. Usaremos um pouco dessa cárie para analisar as bactérias presentes dentro do dente. Depois disso, faremos a restauração do dente com resina composta (material da mesma cor que o dente).

Depois de uma semana, e 1 ano, o voluntário voltará para a faculdade para mostrar a restauração para os dentistas, onde um exame será feito, para que se possa avaliar o tratamento efetuado. Essa pesquisa não envolve riscos aos participantes, uma vez que o uso do laser já é consagrado pelos pesquisadores, mas se ocorrer algum dano aos participantes, os mesmos serão indenizados. Além disso, se necessário os participantes serão ressarcidos de eventuais gastos oriundos de sua locomoção e alimentação. Dessa forma, além de um tratamento sem dor, os participantes terão como vantagem, um acompanhamento clínico por 
um período de no mínimo 1 ano, onde o tratamento será avaliado e se necessário serão efetuados novos procedimentos. O voluntário terá como benefício o tratamento dos dentes cariados, e ainda receberá um kit de higiene oral (escova, pasta e fio dental). Um dentista vai ensinar como devemos cuidar dos nossos dentes e mostrar a importância de comer alimentos adequados.

Como responsáveis por esta pesquisa, declaramos que acompanharemos e daremos assistência a todos os voluntários participantes durante ou após a pesquisa. Caso alguém queira desistir de participar da pesquisa, não terá nenhum problema ou prejuízo.

Declaramos também que haverá sigilo de dados confidenciais ou de algo que provoque qualquer tipo de constrangimento ao voluntário. Todos os dados serão anônimos.

Qualquer reclamação e ou insatisfação por parte dos voluntários durante a pesquisa poderá ser informada a Secretaria do Comitê de Ética em Pesquisa da FORP-USP pelo contato com a secretária Ana Aparecida Ferreira do Nascimento pelo telefone (16) 3602-0251, desde que os reclamantes se identifiquem, sendo que seu nome será mantido em segredo.

Li, compreendi, concordo em participar da referida Pesquisa, por isso assino este documento.

Atenciosamente,

Declaro que entendi os objetivos, riscos e benefícios de minha participação na pesquisa e concordo em participar: 


\section{ANEXo B}

\section{UNIVERSIDADE DE SÃO PAULO}

Faculdade de Odontologia de Ribeirão Preto

Comitê de Ética em Pesquisa

Of.CEP 046/2013

Ribeirão Preto, 22 de março de 2013.

Ref. processo no 2010.1.159.58.3

CAAE n० 0014.0.138.000-10

Senhor Pesquisador,

Por ordem do Senhor Coordenador, informamos que o Comitê de Ética em Pesquisa, em sua 146a Sessão, realizada em 21 de março de 2013, aprovou o Relatório Parcial e a inclusão da pesquisadora Silvana Aparecida Fernandes Polizeli no projeto de pesquisa envolvendo seres humanos intitulado "Estudo in vivo do laser de Er:YAG em dentes decíduos. Análise da sensibilidade dentária, eficácia e eficiência na remoção de lesões de cárie, avaliação microbiológica das cavidades preparadas e das restaurações realizadas".

Salientamos a necessidade de entregar na Secretaria do Comitê, com os formulários preenchidos pelo pesquisador responsável, o Relatório Parcial em 16/06/2013.

Atenciosamente,

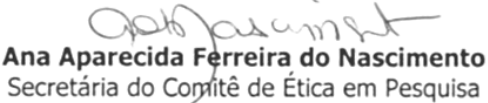

Ilmo(a). Sr(a).

Rodrigo Alexandre Valério

Departamento de Odontologia Restauradora

desta Faculdade 


\section{Anexo C}

\section{Ficha de Anamnese}

Identificação do Paciente:

\begin{tabular}{|l|l|}
\hline Nome: & \\
\hline Data de Nascimento: & \\
\hline Telefone: & \\
\hline Documento: & \\
\hline Endereço: & \\
\hline Filiação: & \\
\hline Data: & \\
\hline & \\
\hline & \\
\hline
\end{tabular}

Em caso de emergência, contactar:

\begin{tabular}{|l|l|l|l|}
\hline Nome: & & Telefone: & \\
\hline Médico: & & Telefone: & \\
\hline
\end{tabular}


Responda às questões abaixo, marcando a resposta com um X:

\begin{tabular}{|c|c|c|c|c|c|c|c|}
\hline 01 & No momento está em tratamento médico? & ( ) & Sim & ( ) & Não & ( ) & Não sei \\
\hline 02 & Está tomando alguma medicação no momento? & ( ) & Sim & ( ) & Não & ( ) & Não sei \\
\hline 03 & Tem ou teve alguma doença como hepatite, sífilis,... & ( ) & Sim & ( ) & Não & ( ) & Não sei \\
\hline 04 & Você é hemofílico? & ( ) & Sim & () & Não & $($ ) & Não sei \\
\hline 05 & Às vezes, sente o coração bater muito rapidamente? & ( ) & Sim & ( ) & Não & ( ) & Não sei \\
\hline 06 & Sofre de alguma doença no coração? & ( ) & Sim & ( ) & Não & ( ) & Não sei \\
\hline 07 & Sente falta de ar com frequência? & ( ) & Sim & ( ) & Não & ( ) & Não sei \\
\hline 08 & Tem tosse persistente com freqüência? & ( ) & Sim & ( ) & Não & ( ) & Não sei \\
\hline 09 & Costuma ter os pé ou pernas inchados? & ( ) & Sim & ( ) & Não & ( ) & Não sei \\
\hline 10 & Alguma vez escarrou sangue? & ( ) & Sim & ( ) & Não & ( ) & Não sei \\
\hline 11 & Você é diabético? & ( ) & Sim & ( ) & Não & ( ) & Não sei \\
\hline 12 & Costuma sentir muita sede? & ( ) & Sim & ( ) & Não & ( ) & Não sei \\
\hline 13 & Quando se fere, as feridas demoram a cicatrizar? & ( ) & Sim & ( ) & Não & ( ) & Não sei \\
\hline 14 & Sangra muito quando se fere? & $($ ( ) & Sim & ( ) & Não & ( ) & Não sei \\
\hline 15 & Tem algum tipo de alergia? & ( ) & Sim & ( ) & Não & ( ) & Não sei \\
\hline 16 & Já precisou de transfusão de sangue? & ( ) & Sim & ( ) & Não & ( ) & Não sei \\
\hline 17 & Alguma vez tomou Penicilina? & ( ) & Sim & ( ) & Não & ( ) & Não sei \\
\hline 18 & Você está grávida? & ( ) & Sim & ( ) & Não & $($ ) & Não sei \\
\hline
\end{tabular}

DECLARO que o respondido acima é verdadeiro.

de de20 
Odontogramas:

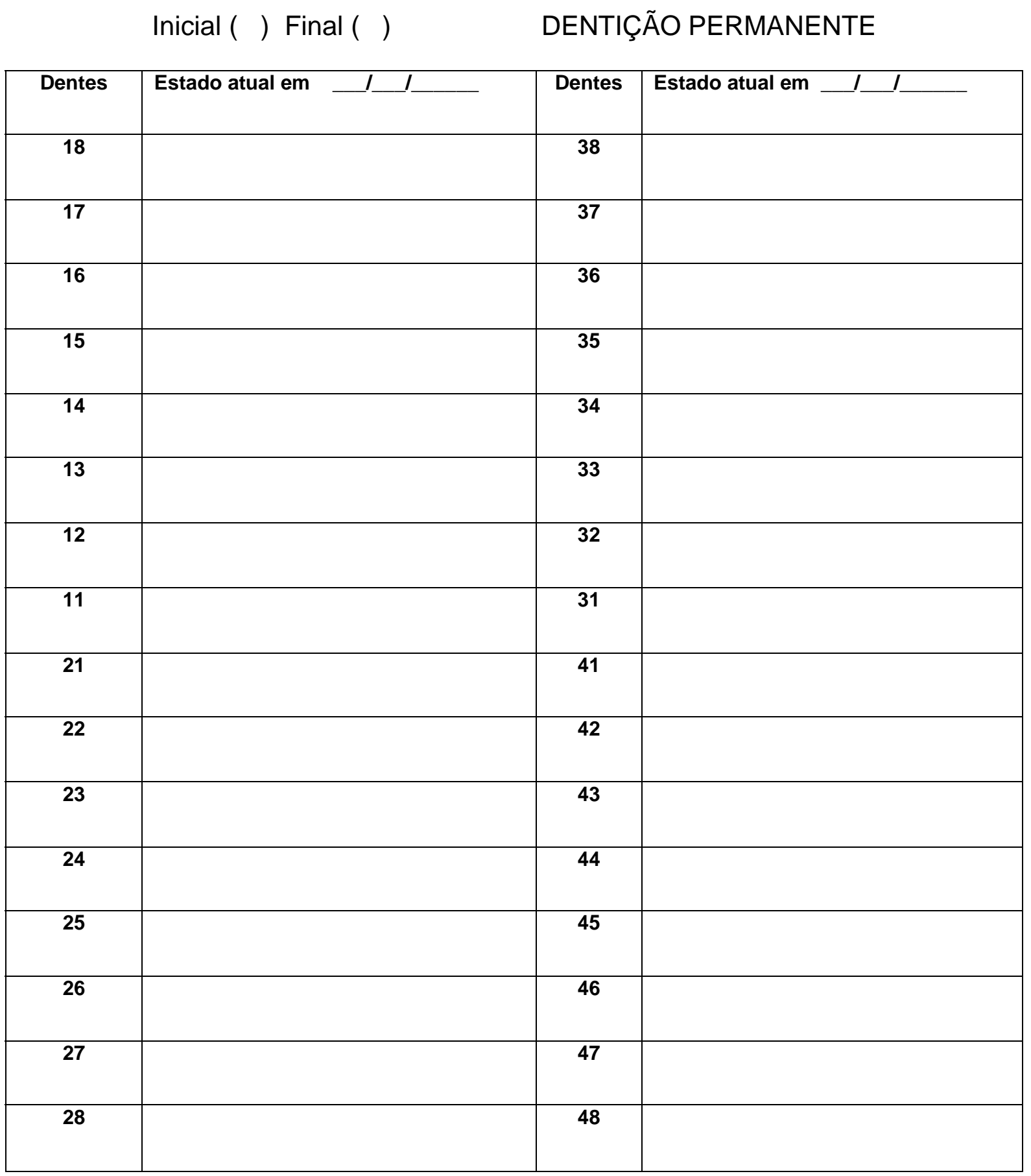


Inicial ( ) Final ( )

DENTIÇÃO DECÍDUA

\begin{tabular}{|c|c|c|c|}
\hline Dentes & Estado atual em _ & Dentes & Estado atual em _ I I I \\
\hline 55 & & 75 & \\
\hline 54 & & 74 & \\
\hline 53 & & 73 & \\
\hline 52 & & 72 & \\
\hline 51 & & 71 & \\
\hline 61 & & 81 & \\
\hline 62 & & 82 & \\
\hline 63 & & 83 & \\
\hline 64 & & 84 & \\
\hline 65 & & 85 & \\
\hline
\end{tabular}

